\title{
Lidil
}

Revue de linguistique et de didactique des langues

$40 \mid 2009$

La motivation pour l'apprentissage d'une langue seconde

\section{Adami Hervé, La formation linguistique des migrants, CLE international, 2009, 128 pages.}

Marielle Rispail

\section{OpenEdition}

\section{Journals}

Édition électronique

URL : http://journals.openedition.org/lidil/2891

DOI : $10.4000 /$ lidil.2891

ISSN : 1960-6052

Éditeur

UGA Éditions/Université Grenoble Alpes

Édition imprimée

Date de publication : 1 décembre 2009

Pagination : 159-160

ISBN : 978-2-84310-154-0

ISSN : $1146-6480$

Référence électronique

Marielle Rispail, « Adami Hervé, La formation linguistique des migrants, CLE international, 2009, 128

pages. », Lidil [En ligne], 40 | 2009, mis en ligne le 01 juin 2011, consulté le 22 septembre 2020. URL http://journals.openedition.org/lidil/2891 ; DOI : https://doi.org/10.4000/lidil.2891

(C) Lidil 


\section{Notes de lecture}

\section{Adami Hervé, La formation linguistique des migrants, CLE international, 2009, 128 pages.}

Comme ne le dit pas son titre, ce courageux petit ouvrage, issu de recherches théoriques et de l'expérience de son auteur et destiné aux enseignants, s'attaque à un sujet encore bien peu traité dans la littérature didactique, celui de l'enseignement non seulement aux adultes, mais encore aux adultes migrants. Il n'est que de parcourir sa bibliographie pour voir en effet que ce domaine y est peu représenté, voire pas du tout. En effet, si nombre de titres s'intéressent aux «migrants» adultes, sous l'angle sociologique, voire sociolinguistique, si les préoccupations «adultes » sont prises en charge par les réflexions sur le FOS (français sur objectifs spécifiques) ou la littéracie (ou littératie), en revanche, l'adulte migrant, comme apprenant spécifique d'une langue, est rarement envisagé en tant que tel. L'excellent ouvrage de Hervé Adami vient combler ce vide, avec modestie et exhaustivité - ce qui est un exploit en 128 pages!

Hervé Adami ${ }^{1}$ prend son lecteur par la main pour le guider, à travers la diversité des situations de migrants en France, issus de contextes historiques, géographiques et politiques variés, vers les structures institutionnelles susceptibles de les accueillir, à l'intérieur desquelles prennent place d'éventuelles instances d'enseignement. Il nous place ainsi du côté de ces adultes, arrivés d'ailleurs, porteurs de savoirs et de savoirfaire rarement explorés, et de leurs besoins spécifiques, tout aussi rarement décrits. L'auteur essaie ainsi de cerner l'identité de ce public qui échappe aux catégories courantes de la didactique, que les formateurs en langue rencontrent souvent dans l'urgence d'une formation professionnelle, et qui permet à la réflexion didactique de remettre en question ses certitudes et de se renouveler.

1. Maitre de conférences à l'université Nancy 2, membre du laboratoire ATILF (équipe CRAPEL), CNRS, UMR 7118. 
Prise en compte des acquis antérieurs, attente d'un minimum vital quasi immédiat en réception écrite, passage par l'oral pour accéder à la lecture, tout est mis à profit pour construire une méthodologie didactique qui, au-delà d'un enseignement linguistique, reconnait le migrant adulte comme un acteur social et le mène vers une découverte culturelle et l'insertion éventuelle, si elle est souhaitée, dans le pays d'accueil. Ce faisant, Hervé Adami ne fuit pas le risque de faire, en $2^{\mathrm{e}}$ partie de l'ouvrage, des propositions concrètes, qui s'enracinent fortement dans la première partie, analytique et contextuelle. Il plaide ainsi, au-delà des migrants adultes, pour une didactique socialement et professionnellement située, ce qui lui permet des mises au point conceptuelles sur des mots souvent galvaudés, comme ceux du tryptique «intégration, littéracie, alphabétisation» qui lui sert de sous-titres. Parfaitement au fait de son sujet, sachant manier anecdotes et références éclairantes, il parcourt avec brio l'arc qui va de la théorie aux pratiques d'enseignement, en passant par l'ancrage social qui leur donne sens et cohérence. Il fait, pour ainsi dire, «son marché» parmi les diverses théories didactiques à sa disposition pour proposer une synthèse originale et pertinente pour son public. Le lecteur appréciera particulièrement le souci qu'a l'auteur de ne pas enfermer l'apprenant adulte migrant dans une situation de demandeur d'emploi qui en ferait un «sous-apprenant linguistique» aux objectifs bornés. Adami est particulièrement convaincant dans les dernières sections de son ouvrage où il montre comment la «voie actionnelle» qu'il propose et l'approche socio-didactique qu'il adopte peuvent déboucher sur la découverte d'autres écrits, d'autres textes, d'autres situations langagières «qui ouvrent eux-mêmes d'autres horizons» en dépassant le seul objectif professionnel. Laissons-lui la parole pour conclure: «Cette démarche est envisageable pour d'autres objectifs fonctionnels selon les besoins des apprenants: consommation, suivi scolaire des enfants ou santé par exemple.» Sa perspective s'inscrit donc dans une démarche d'intégration sociale des migrants, qui prend en charge tout l'individu, dans ses dimensions familiale, citoyenne, économique et politique.

Marielle Rispail

CEDICLEC, université Jean Monnet-St-Étienne LIDILEM, université Stendhal-Grenoble 3 